\title{
No Trust vs. Some Trust in a Game Framed as Trust or Investment: Avoiding the Distrustor
}

\author{
Anna Macko ${ }^{1}$
}

Submitted: 22.10.2019. Accepted: 23.10.2020

\section{Abstract}

Purpose: The study aimed at examining how observing a person showing no trust or some trust, in interaction framed as a trust or an investment, influences two variables: anticipated dissatisfaction from cooperating with the trustor and willingness to avoid such a person in future cooperative tasks. Additionally, the perception of the trustor and anticipated feelings in the role of the trustee were analyzed.

Methodology: A scenario describing the trust game framed as trust or investment was used in the study. Participants $(\mathrm{N}=166)$ were randomly assigned to one of the four conditions: 2 (amount sent in the game: zero vs. one-tenth of the endowment) x 2 (game framing: trust vs. investment) and after reading the scenario made three types of evaluations: (1) their feelings in the position of the trustee from the scenario; (2) the trustor's sociability, morality, and competence and (3) anticipated dissatisfaction from cooperating with the trustor in the future, and finally (4) willingness to avoid the trustor in future interactions.

Results: Interaction effects were found for evaluations of anticipated dissatisfaction from cooperating with the trustor and willingness to avoid the trustor in future interactions. Observing sending nothing in the trust game framed as trust, rather than investment, resulted in stronger anticipated dissatisfaction from cooperating in the future with the trustor, and stronger willingness to avoid such a person as a partner for cooperation. Moreover, independent of the framing of the game, in condition of no trust, participants reported stronger negative feeling when imagining themselves in the role of the trustee and perceived the trustor as less sociable and less competent. Surprisingly, the perception of trustor's morality did not differ across the conditions.

Conclusions: Observing distrust, particularly when the interaction is interpreted in social terms as trust, rather than in economic ones as non-investing, with all other aspects of the situation the same, results in different attitude towards the distrustor on the side of observers. Distrust, in comparison to just non-investing, evokes in observers a stronger propensity to avoid such the distrustor as a partner for cooperation and lowers their anticipated satisfaction from cooperation with him/her.

Keywords: trust game, investment game, distrust, avoidance.

JEL: D91

1 Kozminski University, 59 Jagiellonska St., 03-301 Warsaw, Poland; https://orcid.org/0000-0002-1986-009X, e-mail: amacko@kozminski.edu.pl. 


\section{Introduction}

Trust - "allowing oneself to be vulnerable to the exploitation by another person in order to achieve some benefit and reward" (Dunning, Fetchenhauer and Schloesser, 2016, p. 5) is an indispensable condition for social and market relations to function and thrive. Understanding better what drives people's decisions to trust others is of practical interest - since it would enable some actions that could increase trust, and subsequently improve the functioning of societies.

One of the most often used ways of measuring trusting behavior is the trust game (Berg, Dickhaut and McCabe, 1995). The trust game is a game between two players: the trustor and the trustee. In the standard version of the game, both players are endowed with some money. The trustor can send any amount from their endowment to the trustee. During money transmission, this amount is (usually) tripled. The trustee decides whether to send anything back to the trustor (Berg, Dickhaut and McCabe, 1995). The amount sent to the trustee is a measure of trust since the decision to pass the money stems from "a willingness to bet that another person will reciprocate a risky move (at the cost of themselves)" (Camerer, 2003, p. 85), while the amount sent back to the trustor is a measure of trustworthiness.

Dunning et al. (2014) showed that the tendency to transfer money in the trust game evokes feelings typical of a situation of norm compliance. Their respondents admitted that not sending any money would result in stronger negative arousal and tension than giving money despite low expectations regarding reciprocation. These emotions were significantly correlated with the decisions to transfer money (show trust). Thus, sending something in the trust game seems to be regulated by some kind of normative expectations. Dunning offered an interesting view on trust as being driven by the norm of showing respect (Dunning et al., 2014; Dunning et al., 2012, 2016). People facing a decision of trust are under the pressure of not sending a signal of questioning the character and moral integrity of people they are interacting with. Putting it simply, in line with the norm of respect, we should not insult other people when dealing with them; we should not call into question the character or goodwill of others, if they had not provided us with the evidence justifying such questioning. Consequently, when in the position of a trustor in the trust game, we should avoid sending nothing because it would confirm our negative evaluation of the trustee.

The violation of moral and social norms arouses punitive reactions in the victims and the observers. Thus, the lack of propensity to punish a particular behavior suggests that this behavior is not seen as a violation of any norm. Bicchieri, Xiao, and Maldoon 
(2011) showed that people do not expect punishment - nor are willing to punish - for not revealing trust in the trust game, but they are willing to punish for not reciprocating trust. Punishment in that study took the form of reducing a person's resources: subtracting a specific amount from each of their monetary units obtained in the experiment. Bicchieri et al. (2011) drew from these results a conclusion that there is a norm of reciprocating trust but there is no norm of showing trust.

A question arises whether unwillingness to deduct money from the distrustor and not expecting others to be willing to punish the distrustor in such a way is unequivocally a confirmation of the unwillingness to punish distrust. There are several arguments suggesting that it may not be the case. First, we have to keep in mind that there are different forms of reaction to norm violations and different types of punishment. Punishment can be direct - e.g. fines, reduction of the perpetrator's resources (as in Bicchieri et al.'s (2011) study) or indirect, like gossip (reputation damage) or ostracism (Feinberg, Willer and Schultz, 2014; Liddell and Kruschke, 2014). And indirect punishment might be quite effective for inducing and maintaining cooperation, as research shows (e.g. Wu et al., 2016).

The type of punishment used in a particular situation significantly depends on the costs associated with the execution of punishment and the type of norm being violated. Fines or confrontation are costly while gossip and avoidance of the perpetrator are cheap forms of punishment (Liddell and Kruschke, 2014; Kemper and Newheiser, 2018). Ostracism - "a refusal of repeat business with the punished party" (Liddell and Krusche, 2014, p. 524) is not only cheaper than fines but also more frequent in everyday punishment, as seen in anthropological literature (e.g. Baumard, 2010; 2011). Kemper and Newheiser (2018) who examined propensity to punish by avoidance and confrontation across different moral domains (Care, Fairness, Liberty, Authority, Loyalty, and Sanctity; Graham et al., 2013) found that confrontation was less likely than avoidance, particularly for purity violations (Sanctity domain). Moreover, even though in the case of other types of violations the tendency to avoid norm violators was not as strong as it was in the case of purity violations, still participants were significantly more prone to avoid than to confront liberty, authority, and loyalty violators. Thus, rather than the deduction of distrustor's resources, we observe avoidance in response to withholding trust.

The trust game used to behaviorally measure trust is an interaction that is both social and economic in nature since it involves the exchange among people and the benefits of that exchange are financial. This duality of the nature of interaction in trust game matches a very basic classification of relations between people as either "communal" 
or an "exchange" (Clark and Mills, 1993). These relationship orientations differ with respect to the rules governing social exchange. Communal relationships follow the norm of mutual responsiveness, a widely understood concern for the welfare of the other, and the voluntary provision of benefits to one another with no mental accounting for the investment made. Exchange relationships in turn follow the principle of giving something in return for something, evoking the norm of reciprocity, and employing the rational consideration of cost and benefits.

The dual nature of the interaction in the trust game is also evident in its name since the game can be called either a trust game or an investment game (Berg et al., 1995; Johnson and Mislin, 2011). Though these two names can be used interchangeably, the very same interaction in the game might be interpreted slightly differently, depending on the label of the game. The label "trust", emphasizing the social aspect of the interaction, strengthens the impact of the abovementioned communal rules of conduct while the label "investment", emphasizing the economic aspect strengthens the impact of "exchange" rules of conduct on the interaction. As already mentioned, communal rules focus on the concern for the welfare of others while exchange rules focus on the rational cost and benefits analysis and, subsequently, on self-interest. By putting the welfare of others in focus, the norm of respect should exert a stronger impact on guiding a person's behavior when the situation is interpreted as being subject to communal rules of conduct. Thus, violating the norm of respect should be more evident when the game is framed as a trust rather than as an investment game. Subsequently, zero transfer in the trust game, being more likely to be interpreted as a norm violation than zero transfer in the investment game, should result in a stronger willingness to punish the distrustor in the former than in the latter situation.

Support for the existence of differences in behavior depending on the name of the game comes from several studies. Small changes in the description of the situation (e.g. of a game) can influence individuals' behavior (Gerlach and Jaeger, 2016; Liberman, Samuels and Ross, 2004). More cooperative behavior in prisoners' dilemma was observed when the game was framed as an "international negotiation" than when it was framed as a "business transaction" (Eiser and Bhavani, 1974). Similarly, more cooperation was observed when the game was labeled as a "Community Game" than when it was labeled a "Wall Street Game" game (Kay and Ross, 2003; Liberman et al., 2004).

Withholding trust in the trust game is generally harmful to the decision-maker's reputation. Kruger et al.'s (2008) study showed that different decisions in the trust game resulted in different trait attributions. They examined attributions of morality and competence following trustor's decisions in the trust game. Their results revealed 
stronger dependence on the entrusted amounts in the case of attributions of morality than competence, but still, those sending nothing were seen as less moral and less competent than those sending a partial amount of their endowment. Evans et al. (2018) in turn examined the impact of generalized trust (not behavioral trust as measured in trust game) on three dimensions of social perception: morality, sociability, and competence. They found that high-trust individuals were perceived as more moral and more sociable but not more competent.

Usual transfer in trust games oscillates around 40-50\% (see e.g. Johnson and Mislin, 2011). Not sending anything in the trust game suggests prioritizing the goal of securing one's resources over other goals. However, such a decision, additionally to sending the information about limited interest in generating gains, can also be a signal of offense - questioning the trustee's good character or goodwill - when the situation is perceived in communal, social terms. Making a very cautious choice - sending significantly less than $\sim 40-50 \%$ (e.g. 10\%) of trustor's endowment does not present the trustor as a profit-oriented partner but nevertheless presents him as willing to conform to the norm of respect. By sending a very small part of the endowment, the trustor avoids sending a signal of questioning the moral integrity of the partner without sufficient reason, and at the same time secures his resources, since the potential loss in the case of the lack of reciprocation is very small. Thus, people in cooperative contexts generally should be willing to avoid partners that are very cautious and reluctant to take social risks, but if the potential partner also transgresses normative expectations imposed by communal rules of conduct, people should be even more willing to avoid interacting with such a person.

\section{Present study}

The ability to generate benefits is one of the factors influencing the partner's choice for cooperation (Martin, Young and McAuliffe, 2019). Thus, very cautious people, who, being trustors in a trust game, keep their endowment or send a very small fraction of it would rather be avoided as partners for cooperative tasks. However, a comparison of the tendency to avoid the trustor who sends very little or nothing in different contexts - activating communal/social vs. transactional/ economic rules of conduct - should allow gaining some insight into the willingness to punish distrust, not solely unwillingness to generate gains. If there is a difference in the propensity to avoid the distrustor depending on the interpretation of the situation - as subject to communal vs. transactional rules of conduct - with a stronger willingness to avoid him in the former than in the latter, stronger avoidance can be seen as a form of punishing the violation of 
normative expectations imposed by the rule of respect, in addition to the failure to generate benefits.

The goal of the study was threefold:

(1) to examine whether people will be more prone to avoid a person who shows no trust than a person who shows some trust (though very limited);

(2) to examine reputational and emotional consequences of showing distrust;

(3) to examine whether responses to distrust will be stronger when the game is framed as a situation of trusting (social, communal) rather than investing (economic, transactional) interaction.

Two descriptions of the trust game were used, one using expressions presenting the game as trust and the other as an investment interaction, with a trustor sending either nothing (no trust condition) or sending $1 / 10^{\text {th }}$ of his endowment (some trust condition). Participants were asked to put themselves in the position of the trustee and evaluate their feelings after the trustor's decision (zero or $1 / 10^{\text {th }}$ of the endowment, depending on the group), then to evaluate the trustor's sociability, morality, and competence, and finally their anticipated satisfaction with having to work with the trustor in some future task as well as their inclination to avoid the trustor - to prefer another, unknown partner, for future collaboration.

As already mentioned, a person sending a very small amount should be avoided as an unattractive partner for collaboration, for producing benefits, but a person sending nothing should be avoided even more, particularly in a communally framed game, due to an offense inherent in the decision to withhold trust.

It was hypothesized that:

H1: People will be more willing to avoid a person who showed no trust than a person who showed some trust in interacting with others, and the effect will be stronger when the game is framed as a trust rather than an investment game.

Entrusting nothing vs. something has an impact on the reputational consequences for the (dis)trustor. As already mentioned, studies by Kruger et al. (2008) and Evans et al. (2018) showed that zero transfer in the trust game lowered the player's perceived morality, sociability, and competence. However, if withholding trust is a violation of the moral norm, the framing of the game should additionally impact attributions of the trustor's morality. Thus, it was hypothesized: 
H2: People will attribute less morality, sociability, and competence to a person who shows no trust than to a person who shows some trust, and in the case of morality attributions, the effect will be stronger when the game is framed as a trust rather than an investment game.

Since an act of withholding trust not only prevents obtaining some benefits but also - in situations that are subject to communal rules of conduct - questions distrusted party's moral character and goodwill, it was hypothesized that:

H3: People will report stronger negative feelings when imagining themselves in the role of distrusted trustee than in the role of the trustee entrusted with some small amount, and the effect will be stronger when the game is framed as a trust rather than an investment game.

H4: People will anticipate less satisfaction from cooperating with a person who showed no trust than with a person who showed some trust in interacting with others, and the effect will be stronger when the game is framed as a trust rather than an investment game.

\section{Method}

\section{Participants}

A group of 245 participants took part in the study, with 79 failing to understand the game, leaving 166 participants eligible for the analyses. Out of those 166 participants, 84 took part in the game framed as a trust (44 in no trust and 40 in sending 1/10 of the endowment condition) and 82 in the game framed as an investment game (40 in no trust and 42 in sending $1 / 10^{\text {th }}$ of the endowment condition); 92 were female. The mean age of participants was $M=22.79 ; S D=4.52$.

\section{Materials and Procedure}

Participants read a scenario - the description of the trust game played between two players: a trustor and a trustee. The description presented the game either as a trust game or an investment game, by using such labels over the description of the game and the verbs "trust" or "investment" in the game description. The content of the description was identical - in both (trust and investment) versions of the game, the trustor entrusted either nothing or $1 / 10^{\text {th }}$ of his endowment. Thus, there were four versions 
of the scenario - 2 (amount sent in the game: nothing or $1 / 10^{\text {th }}$ of his endowment) $\times 2$ (game framing: trust vs. investment), and each participant saw only one scenario.

After reading the description of the game, answering questions examining one's understanding of the game, participants made the following judgments. First, they evaluated the feelings they would experience in the role of the trustee in the described game. Then they evaluated 12 traits of the trustor. Next, they evaluated their (dis)satisfaction with the prospect of having the trustor from the game as a partner in another task requiring cooperation. Finally, the participants evaluated how much they would prefer to avoid cooperation with the trustor in the future (for the English translation of instructions used in the study, see the Appendix). Subsequent steps of the experimental procedure are presented in Figure 1.

Figure 1. Stages of experimental procedure

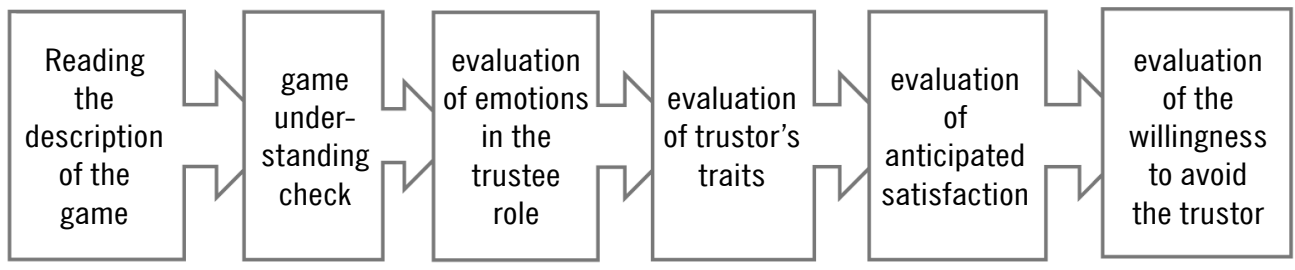

Source: own elaboration.

\section{Measures}

Trustor's Avoidance. Participants were asked to imagine a future cooperation project for which they could choose a partner. The project referred to the idea of cooperation, but it did not specify the task because it was intended to capture participants' general intention to establish cooperative relations with the trustor. By placing a mark on a $10 \mathrm{~cm}$ line - with one pole of the line labeled as "definitely Adam (the trustor from the scenario described above)" and the other pole labeled as "definitely somebody else than Adam (the trustor from the scenario described above)" - the participants evaluated which partner they would prefer. The further from the pole "definitely Adam" the mark appeared on the line the stronger was the participant's willingness to avoid the trustor. Thus, the higher the number the weaker the tendency to avoid the trustor described in the scenario in future interactions.

Anticipated Satisfaction from Future Cooperation with the Trustor. Participants were asked to imagine a future cooperation project - again without specifying the type of 
the project - for which they would have the trustor from the scenario assigned as a partner. By placing a mark on a $10 \mathrm{~cm}$ line - with one pole of the line labeled as "definitely unhappy" and the other pole labeled as "definitely happy" - the participants evaluated how they would feel in such a situation. Thus, the higher the value on the scale the higher the anticipated satisfaction from cooperating with the trustor described in the scenario in future interactions.

Negative Feelings. Participants indicated on the 7 point scale $(0$ - definitely not, 6 - definitely yes) the strength of five emotional states (irritated, sad, disappointed, content (recoded), happy (recoded) they would feel if they were the trustee in the game from the scenario. The mean value of five emotions served as an index of negative feelings experienced in the role of the trustee (Cronbach's $\alpha=.79$ ).

Trustor's Perception. Participants indicated on the seven-point scale (0 - definitely not, 6 - definitely yes) their impression of 12 traits of the trustor. Factor analysis with Oblimin rotation revealed a three-factor solution, explaining $63.50 \%$ of the variance. Three factors represented three dimensions of social perception: morality (honest and fair, $\alpha=.81$ ), sociability (friendly, kind, nice and polite, $\alpha=.84$ ), and competence (intelligent, competent, ambitious, and efficient, $\alpha=.78$ ).

\section{Results}

\section{Avoidance of the Trustor from the Scenario}

As seen in Table 1, the strongest propensity to avoid the distrustor in future interactions was found in the group with trust framing and zero transfer in the game. A Kruskal-Wallis $\mathrm{H}$ test was conducted to compare willingness to avoid the trustor across four groups: the trustor sending nothing in the game framed as trust or as investment, and the trustor sending $1 / 10^{\text {th }}$ of his endowment in the game framed as trust or as investment. The test showed that there was a statistically significant difference in the willingness to avoid the trustor in these groups, $H(3)=12.362, p=.006$, with the mean rank of avoidance score of 102.70 for zero transfer in a trust-framed game, 83.65 for zero transfer in an investment framed game, 66.45 for one-tenth transfer in a trust-framed game, 79.48 for one-tenth transfer in an investment-framed game. Pairwise comparisons with $U$ Mann-Whitney tests were conducted and revealed significant differences between groups with zero and $1 / 10^{\text {th }}$ transfer in a trust-framed game ( $\mathrm{p}=.056$, two-tailed) and between zero transfer in a trust-framed and zero transfer in an investment-framed game $(\mathrm{p}<.001$, two-tailed). 
Table 1. Means and standard deviations (in brackets) of the measured variables in two groups: with the game framed as trust and as investment game

\begin{tabular}{|c|c|c|c|c|c|c|c|c|}
\hline & \multicolumn{4}{|c|}{ TRUST GAME } & \multicolumn{4}{|c|}{ INVESTMENT GAME } \\
\hline & \multicolumn{2}{|c|}{ Sends nothing } & \multicolumn{2}{|c|}{$\begin{array}{l}\text { Sends } 1 / 10 \text { th } \\
\text { of the endowment }\end{array}$} & \multicolumn{2}{|c|}{ Sends nothing } & \multicolumn{2}{|c|}{$\begin{array}{l}\text { Sends } 1 / 10 \text { th } \\
\text { of the endowment }\end{array}$} \\
\hline & Mdn & M (SD) & Mdn & M (SD) & Mdn & $M(S D)$ & Mdn & $M(S D)$ \\
\hline $\begin{array}{l}\text { willingness to avoid } \\
\text { the trustor }\end{array}$ & 8.15 & $\begin{array}{c}8.01 \\
(1.36)\end{array}$ & 6.90 & $\begin{array}{c}6.59 \\
(2.01)\end{array}$ & 7.40 & $\begin{array}{c}7.34 \\
(1.79)\end{array}$ & 7.25 & $\begin{array}{c}7.00 \\
(2.30)\end{array}$ \\
\hline trustor's morality & 3.00 & $\begin{array}{l}2.84 \\
(0.83)\end{array}$ & 3.00 & $\begin{array}{l}2.54 \\
(0.97)\end{array}$ & 3.00 & $\begin{array}{l}2.80 \\
(1.07)\end{array}$ & 3.00 & $\begin{array}{l}3.08 \\
(1.05)\end{array}$ \\
\hline trustor's sociability & 2.12 & $\begin{array}{l}1.91 \\
(0.76)\end{array}$ & 2.75 & $\begin{array}{c}2.69 \\
(1.03)\end{array}$ & 2.12 & $\begin{array}{c}2.11 \\
(0.88)\end{array}$ & 2.75 & $\begin{array}{c}2.65 \\
(0.79)\end{array}$ \\
\hline trustor's competence & 2.50 & $\begin{array}{c}2.52 \\
(1.00)\end{array}$ & 3.00 & $\begin{array}{c}2.95 \\
(0.89)\end{array}$ & 2.75 & $\begin{array}{c}2.68 \\
(1.54)\end{array}$ & 3.25 & $\begin{array}{l}3.22 \\
(1.00)\end{array}$ \\
\hline $\begin{array}{l}\text { negative affect } \\
\text { in the role of the trustee }\end{array}$ & 3.67 & $\begin{array}{l}3.90 \\
(0.84)\end{array}$ & 3.41 & $\begin{array}{c}3.09 \\
(1.15)\end{array}$ & 3.58 & $\begin{array}{l}3.75 \\
(0.90)\end{array}$ & 3.17 & $\begin{array}{c}3.14 \\
(1.22)\end{array}$ \\
\hline $\begin{array}{l}\text { anticipated satisfaction } \\
\text { from cooperation }\end{array}$ & 1.70 & $\begin{array}{c}1.71 \\
(1.33)\end{array}$ & 2.80 & $\begin{array}{c}3.32 \\
(1.99)\end{array}$ & 2.45 & $\begin{array}{c}2.63 \\
(1.65)\end{array}$ & 3.00 & $\begin{array}{c}3.26 \\
(2.53)\end{array}$ \\
\hline
\end{tabular}

Source: own elaboration.

\section{Perception of the Trustor in the Scenario}

Three 2 (the amount sent: nothing vs. $1 / 10^{\text {th }}$ of the endowment) $\mathrm{x} 2$ (game framing: trust vs. investment) ANOVAs on attributions of trustor's morality, sociability, and competence were conducted. In the case of two dimensions of social perception - sociability and competence - main effects of the amount sent turned out to be significant $\left(F(1,162)=23.78, p<.001, \eta^{2}=.13 ; F(1,162)=9.43, p=.003, \eta^{2}=.06\right.$, respectively $)$. Confirming hypothesis 2 independent of the framing of the game (trust vs. investment)- the trustor who entrusted nothing was seen as less sociable and less competent than the trustor who entrusted one-tenth of the endowment. However, contrary to hypothesis 2, perception of trustor's morality did not differ across conditions (Table 1).

\section{Negative Affect on the Role of Trustee}

In the case of negative feelings reported when imagining oneself in the position of the trustee, a 2 (amount sent: nothing vs. $1 / 10^{\text {th }}$ of the endowment) $x 2$ (game framing: trust vs. investment) ANOVA also revealed a significant main effect of the entrusted 
amount $\left(F(1,162)=19.07, p<.001, \eta^{2}=.11\right)$, with participants reporting feeling more negatively when imagining themselves being entrusted nothing than when imagining themselves being entrusted a small amount, independent of whether the game was described as a trust or an investment game. Thus, hypothesis 3 was not confirmed. Participants did report more negative feelings when putting themselves in the position of the trustee in the game from the scenario; however, framing the game as trust did not affect the strength of their negative feelings (Table 1).

\section{Anticipated Satisfaction from Cooperation with the Trustor}

Just as in the case of trustor's avoidance, a Kruskal-Wallis $\mathrm{H}$ test was conducted to compare anticipated satisfaction from a cooperation with the trustor in the future across four groups: the trustor sending nothing in the game framed as trust or as investment, and the trustor sending $1 / 10$ th of the endowment in the same settings. The test showed that there was a statistically significant difference in the anticipated satisfaction from cooperating with the trustor in these groups, $H(3)=17.160, p=.001$, with the mean rank of avoidance score of 59.17 for zero transfer in a trust-framed game, 84.76 for zero transfer in an investment-framed game, 99.15 for one-tenth-transfer in a trust-framed game, and 92.88 for one-tenth-transfer in an investment-framed game. Pairwise comparisons with $U$ Mann-Whitney tests were conducted and revealed significant differences between groups with zero and 1/10th transfer in a trust framed game $(\mathrm{p}<.001)$ and between zero-transfer in a trust-framed and zero transfer in an investment framed game $(p=.009)$ (Table 1). These results support hypothesis 4 . Anticipated satisfaction was the lowest in the group whose potential partners did not send anything in a trust framed game.

\section{Discussion}

The main contribution of the reported study is an extension of knowledge on the consequences of showing distrust to others. In light of the results, showing distrust rather than just non-investing - when all other aspects of the situation remain the same - evokes in observers a stronger propensity to avoid such a decision-maker as a partner for cooperation and lowers anticipated satisfaction from a cooperation with him/her. People tend to avoid more those whom they observed as sending nothing in the trust game in comparison to those they observed sending something, but still, the propensity to avoid a distrustor is significantly stronger when sending nothing occurred in a situation presented as a more social (trust) than economic (investment) interaction. 
The avoidance of a person when undertaking cooperative activities can be a form of punishment - ostracism. Ostracism as a punishment prevents future transgressions and was found to motivate cooperation in public good games (see Liddell and Kruschke, 2014). However, we should remember that propensity to avoid a person as a potential collaboration partner might be driven by diverse factors. Considering a person as a partner for cooperation definitely requires the evaluation of their ability to generate benefits. Thus, rationally, avoidance of the potential partner is associated with the potential partner's inability to generate benefits. However, it could also be a form of altruistic punishment in response to observed transgression of a norm, assuming that the observers interpret the situation as an instance of norm transgression.

Both choices - sending nothing or sending $1 / 10^{\text {th }}$ of the endowment - do not encourage a willingness to cooperate with the decision-maker since both indicate low ability to generate benefits. As mentioned above, the ability to generate benefits is an important factor that influences the choice of a partner (Martin et al., 2019). It seems rational and obvious to prefer another, unknown person over a person with low ability to generate benefits when choosing a partner for a cooperative task. The amount sent in trust games can be treated as an index of ability to generate benefits, since the bigger the transfer the higher the profits that can be made in the game. Hence, it is understandable that the willingness to avoid cooperation with the trustor was stronger in the case of a person who sent nothing compared to a person who sent a little. Similarly, the anticipated satisfaction from cooperating with a person with a lower ability to generate benefits (zero-transfer condition) was lower than the anticipated satisfaction from cooperating with a person with a slightly higher ability to generate benefits $\left(1 / 10^{\text {th }}\right.$ of the endowment condition). However, the fact that the preference for an unknown person as a partner was stronger and the anticipated satisfaction from the cooperation was lower when the trustor's decision was made in the game framed as trust rather than investment suggests, that - in the case of distrust (in comparison to non-investment) - avoidance is driven by something more than low ability to generate benefits.

The design of the reported study does not allow us to unequivocally identify what is responsible for this difference. However, the most plausible explanation is the punishment for violating the norm that regulates situations of trusting strangers, which Dunning et al.'s (2012; 2014; 2016) identify as the norm of respect. According to the norm of respect, people should not offend others by questioning their goodwill or character if they have no evidence that would justify such a questioning. Sending nothing signals doubts about the trustee's goodwill or character. This game is a situation that can be described by two dimensions: the social one - interacting with another person, and the economic one-, interaction's goal is financial gain. Emphasizing one 
of these dimensions in a particular situation may trigger different rules as the guiding rules of conduct. Framing the game as trust emphasizes social, communal values and rules of conduct, which focus on the welfare of others. Framing the game as an investment emphasizes exchange, economic values, which concentrate on the rational calculation of costs and benefits and self-interest rather than on the welfare of others. Subsequently, questioning the goodwill or character of another person (sending nothing in the trust game) in situations governed by focus on the welfare of others is a clearer violation of the norm of respect than doing the same when self-interest governs the conduct.

The obtained results suggest that the problem of punishing distrust might be more complex than the picture presented by Bicchieri et al. (2011) who concluded that people are not willing to punish for showing distrust. Such a propensity might be quite weak and situation-dependent but still present. It might assume the form of a cheaper way of punishing - that of ostracism (avoiding the distrustor) - than fining (reducing the distrustor's resources), and it may depend on the strength of the social, communal aspect of the interaction, activated at the moment of decision on punishment. Seeing the interaction more in the economic, exchange perspective might weaken the punitive attitude. Still, this reasoning is a possibility suggested by the results of this study rather than a firm conclusion. More research is needed to provide such a conclusion.

Surprisingly enough, the perception of trustor's morality was unaffected either by the amount sent or by the framing of the game. Nevertheless, in line with previous studies (Kruger et al., 2008; Evans et al., 2018), not sending anything in the game had reputational consequences for the perception of trustor's sociability and competence. Not sending anything made the trustor look less social and less competent. In a similar way, anticipated emotional reactions to trustor's decision were more negative when participants imagined themselves in the position of the trustee who received nothing from the trustor than when they imagined themselves as the trustee who received $1 / 10^{\text {th }}$ of the endowment. Contrary to expectations, reputational consequences and anticipated emotional responses were not sensitive to the game's framing. This result is difficult to explain and more research is required to check whether this effect persists or was just accidental in the current study. Maybe it is a consequence of one of the limitations of the study, namely the hypothetical nature of choices and evaluations made by the participants. Particularly, imagining emotional responses to hypothetical situations might be flawed. Thus, a study with a more naturalistic decision-making context, with real choices of partners and cooperation with real consequences would be both very desirable and very informative. 
Moreover, the reported study did not include Bicchieri et al.'s (2011) measure of punishment propensity: the willingness to reduce distrustor's resources. To obtain a more complete answer to the question of whether people punish distrust, a future study that would examine the propensity to employ both forms of punishment - reducing resources and avoiding the distrustor - would be very useful.

As mentioned above, trust is indispensable for the optimal functioning of individuals, organizations, and societies. Thus, a better understanding of the consequences of observing distrust would allow us to plan activities that could mitigate the negative consequences of the lack of trust or inadequate levels of trust. Besides providing preliminary results on the consequences of observing distrust, the current study offers some practical implications, useful for social interactions. Many interactions that involve trust are dual in nature: social, as they involve people, and economic, as they involve exchanges that aim at monetary gains. Results of the present study show that observing trustors reveling lower trust than it is usually seen in these type of situations $^{2}$ leads to avoidance of such trustors in future cooperative tasks. However, in the case of a low but still present trust, the propensity to avoid trustors is hardly impacted by the interpretation of the situation in more communal or exchange terms. Things are different when observing distrust. The propensity to avoid a person showing distrust is impacted by the interpretation of the situation. Thus, by changing the interpretation of the situation one can modify the propensity to avoid the distrustor. In light of the obtained results, emphasis on the economic dimension of the situation rather than the communal, social one in trust interactions involving monetary gains could have a significant positive impact on one's reluctance to engage in future cooperative tasks with the distrustor.

\section{References}

Baumard, N. (2010). Has punishment played a role in the evolution of cooperation? A critical review. Mind \& Society, 9(2), 171-192. http://dx.doi.org/10.1007/s11299-010-0079-9.

Baumard, N. (2011). Punishment is not a group adaptation. Mind \& Society, 10(1), 1-26. http://dx.doi.org/10.1007/s11299-010-0080-3.

Berg, J., Dickhaut, J., and McCabe, K. (1995). Trust, reciprocity and social history, Games and Economic Behavior, 10, 122-142. https://doi.org/10.1006/game.1995.1027.

Bicchieri, C., Xiao, E., and Muldoon, R. (2011). Trustworthiness is a social norm, but trusting is not. Politics, Philosophy \& Economics, 10(2), 170-187. https://doi.org/10.1177/1470594X10387260.

\footnotetext{
2 As a reminder, in the reported study it was $1 / 10^{\text {th }}$ one-tenth of the player's endowment, while the amounts typically sent in trust games oscillate around $40-50 \%$ of the player's endowment.
} 
Camerer, C. (2003). Behavioral game theory: Experiments on strategic interaction. Princeton: Princeton University Press.

Clark, M.S., and Mills, J. (1993). The difference between communal and exchange relationships: What it is and is not. Personality and Social Psychology Bulletin, 19, 684-692.

Dunning, D., Anderson, J. E., Schlösser, T., Ehlebracht, D., and Fetchenhauer, D. (2014). Trust at zero acquaintance: More a matter of respect than expectation of reward. Journal of Personality and Social Psychology, 107(1), 122-141. https://doi.org/10.1037/a0036673.

Dunning, D., Fetchenhauer, D., and Schloesser, T. (2016). The Psychology of Respect A case study of How Behavioral norms regulate human action. In: A. Elliot (ed.), Advances in motivation science (Vol. 3, pp. 1-34). New York, NY: Elsevier. http://dx.doi.org/10.1016/bs.adms.2015.12.003.

Dunning, D., Fetchenhauer, D., and Schlösser, T.M. (2012). Trust as a social and emotional act: Noneconomic considerations in trust behavior q. Journal of Economic Psychology, 33(3), 686-694. https://doi.org/10.1016/j.joep.2011.09.005.

Eiser, J.R. and Bhavnani, K. (1974). The effect of situational meaning on the behaviour of subjects in the Prisoner's Dilemma Game. European Journal of Social Psychology, 4(1), 93-97.

Evans, A.M., and van de Calseyde, P. (2017). The reputational consequences of generalized trust. Personality and Social Psychology Bulletin, 44, 492-507. https://doi.org/10.1177/0146167217742886.

Feinberg, M., Willer, R., and Schultz, M. (2014). Gossip and ostracism promote cooperation in groups. Psychological Science, 25, 656-664. https://doi.org/10.1177/0956797613510184.

Gerlach, P., and Jaeger, B. (2016). Another frame, another game? Explaining framing effects in economic games. Norms, Actions, Games, (June), 1-10. https://doi.org/10.17605/OSF.IO/AB5YP

Graham, J., Haidt, J., Koleva, S., Motyl, M., Iyer, R., Wojcik, S. P., and Ditto, P.H. (2013). Moral foundations theory: The pragmatic validity of moral pluralism. Advances in Experimental Social Psychology, 47, 55-130.

Johnson, N.D., and Mislin, A.A. (2011). Trust games: A meta-analysis. Journal of Economic Psychology, 32(5), 865-889. https://doi.org/10.1016/j.joep.2011.05.007.

Kay, A.C., and Ross, L. (2003). The perceptual push: The interplay of implicit cues and explicit situational construals on behavioral intentions in the Prisoner's Dilemma. Journal of Experimental Social Psychology, 39, 634-643. http://dx.doi.org/10.1016/S0022-1031(03)00057-X.

Kemper, N.S., and Newheiser, A.-K. (2017). To Confront or to Avoid. Social Psychological and Personality Science, 194855061772283. https://doi.org/10.1177/1948550617722831.

Krueger, J.I., Massey, A.L., and DiDonato, T.E. (2008). A matter of trust: From social preferences to the strategic adherence to social norms. Negotiation and Conflict Management Research, 1, 31-52.

Liberman, V., Samuels, S.M., and Ross, L. (2004). The name of the game: Predictive power of reputations versus situational labels in determining Prisoner's Dilemma game moves. Personality and Social Psychology Bulletin, 30, 1175-1185. https://doi.org/10.1177/0146167204264004.

Liddell, T.M., and Kruschke, J.K. (2014). Ostracism and fines in a public goods game with accidental contributions: The importance of punishment type. Judgment and Decision Making, 9(6), 523-547.

Martin, J., Young, L., and McAuliffe, K. (2019). The psychology of partner choice. https://psyarxiv.com/weqhz/.

Wu, J., Balliet, D., and Van Lange, P.A.M. (2016). Reputation, gossip, and human cooperation. Social and Personality Psychology Compass, 10, 350-364. https://doi.org/10.1111/spc3.12255. 


\section{APPENDIX}

\section{Translated instructions used in the study}

Thank you for participating in this study. The study is about the perception of decision-makers in social interactions. As the study is about judgments, not knowledge, there are no "correct" or "wrong" answers. It is important that the answers agree with your beliefs. The research is anonymous, and its purpose is purely scientific.

Read the below descriptions of situations and answer them by typing them in places or on the scales provided. Before submitting your answers, please ascertain you have provided answers to all questions.

\section{TRUST GAME}

Imagine a situation of people participating in a study on decision-making. The participants took part in a game described below.

TRUST GAME: Description of the game

There are two people in this game: Adam (Player 1) and Piotr (Player 2). Adam and Piotr have an endowment of PLN 100 each. From this amount, Adam can entrust any amount of money to Piotr. If Adam entrusts Piotr with some amount, that amount will be tripled before it goes to Piotr. For example, if Adam entrusts Piotr PLN 20, Piotr will eventually receive PLN 60, if he entrusts PLN 50, Piotr will receive PLN 150, etc.

After receiving the money, Piotr can do whatever he wants with them. He may reciprocate the trust Adam showed and give Adam any amount of the money he has received thanks to the trust Adam showed him. For example, if Adam entrusted PLN 20 and Piotr received PLN 60, so Piotr may transfer to Adam any amount from that PLN 60. Piotr can also keep the whole amount to himself.

At the end of the game, players receive payments:

Player 1, Adam, has: 100 - (the entrusted amount) + (the amount received from Piotr)

Player 2, Piotr, has: $100+$ (tripled the amount entrusted by Adam) - (the amount transferred to Adam) 
If Player 1, Adam, entrusted PLN 30 to Piotr then:

How much money goes to Player 2, Piotr?

How much money is left for Player 1, Adam, after entrusting money?

OR

\section{INVESTMENT GAME}

Imagine a situation of people participating in a study on decision-making. The participants took part in a game described below.

There are two people in this game: Adam (Player 1) and Paweł (Player 2). Adam and Paweł have an endowment of PLN 100 each. From this amount, Adam can invest any amount of money by giving it to Paweł. If Adam invests some amount, that amount will be tripled before it goes to Paweł. For example, if Adam invests PLN 20, Paweł will eventually receive PLN 60, if he invests PLN 50, Paweł will receive PLN 150, etc.

After Adam's investment, Paweł can do whatever he wants with the money he receives. He can give Adam any amount of the money he receives from Adam's investment. For example, if Adam invested PLN 20 and Paweł received PLN 60, Paweł can give Adam any amount from that PLN 60. Paweł can also keep the whole sum to himself.

At the end of the game, players receive payments:

Player 1, Adam, has: 100 - (the invested amount) + (the amount received from Paweł)

Player 2, Pawel, has: 100 + (tripled amount invested by Adam) - (the amount transferred to Adam)

If Player 1, Adam, invested PLN 30, then:

How much goes to Player 2, Pawel?

How much is left for Player 1, Adam after investing 


\section{PLAYER 1'S DECISION}

The game was played and it turned out that Player 1, Adam, entrusted nothing from PLN 100 to Player 2, Piotr, [Adam entrusted Player 2, Piotr, with PLN 10 from PLN 100].

\section{How would you feel if you were Piotr, Player 2?}

OR

The game was played, and it turned out that Player 1, Adam, invested nothing out of his PLN 100 and gave nothing to Player 2, Paweł / [Adam invested PLN 10 out of his PLN 100 in Paweł, Player 2].

How would you feel if you were Pawel, Player 2?

\begin{tabular}{|c|c|c|c|c|c|c|c|}
\hline & $\begin{array}{c}\text { I definitely } \\
\text { would not } \\
0\end{array}$ & $\begin{array}{c}\text { I would } \\
\text { not } \\
1\end{array}$ & $\begin{array}{c}\text { I would } \\
\text { rather not } \\
2\end{array}$ & $\begin{array}{c}\text { Difficult } \\
\text { to say } \\
3\end{array}$ & $\begin{array}{c}\text { I would } \\
\text { rather feel } \\
4\end{array}$ & $\begin{array}{c}\begin{array}{c}\text { I would } \\
\text { feel }\end{array} \\
5\end{array}$ & $\begin{array}{c}\text { I definitely } \\
\text { would } \\
6\end{array}$ \\
\hline Surprised & 0 & 1 & 2 & 3 & 4 & 5 & 6 \\
\hline Irritated & 0 & 1 & 2 & 3 & 4 & 5 & 6 \\
\hline Satisfied & 0 & 1 & 2 & 3 & 4 & 5 & 6 \\
\hline Sad & 0 & 1 & 2 & 3 & 4 & 5 & 6 \\
\hline Joyful & 0 & 1 & 2 & 3 & 4 & 5 & 6 \\
\hline Disregarded & 0 & 1 & 2 & 3 & 4 & 5 & 6 \\
\hline
\end{tabular}

Adam seems to you:

\begin{tabular}{|c|c|c|c|c|c|c|c|}
\hline & $\begin{array}{c}\text { He definitely } \\
\text { does not seem } \\
0\end{array}$ & $\begin{array}{c}\text { He does } \\
\text { not seem } \\
1\end{array}$ & $\begin{array}{c}\text { He seems } \\
\text { rather not } \\
2\end{array}$ & $\begin{array}{c}\text { Difficult } \\
\text { to say } \\
3\end{array}$ & $\begin{array}{c}\text { He seems } \\
\text { rather } \\
4\end{array}$ & $\begin{array}{c}\text { He } \\
\text { seems } \\
5\end{array}$ & $\begin{array}{c}\text { He definitely } \\
\text { seems } \\
6\end{array}$ \\
\hline Friendly & 0 & 1 & 2 & 3 & 4 & 5 & 6 \\
\hline Intelligent & 0 & 1 & 2 & 3 & 4 & 5 & 6 \\
\hline Polite & 0 & 1 & 2 & 3 & 4 & 5 & 6 \\
\hline Trustworthy & 0 & 1 & 2 & 3 & 4 & 5 & 6 \\
\hline
\end{tabular}




\begin{tabular}{|c|c|c|c|c|c|c|c|}
\hline Effective & 0 & 1 & 2 & 3 & 4 & 5 & 6 \\
\hline Honest & 0 & 1 & 2 & 3 & 4 & 5 & 6 \\
\hline Fair & 0 & 1 & 2 & 3 & 4 & 5 & 6 \\
\hline Competent & 0 & 1 & 2 & 3 & 4 & 5 & 6 \\
\hline Nice & 0 & 1 & 2 & 3 & 4 & 5 & 6 \\
\hline Ambitious & 0 & 1 & 2 & 3 & 4 & 5 & 6 \\
\hline Sincere & 0 & 1 & 2 & 3 & 4 & 5 & 6 \\
\hline Kind & 0 & 1 & 2 & 3 & 4 & 5 & 6 \\
\hline
\end{tabular}

\section{EXPECTED FEELINGS}

Now imagine that you are taking part in a task/project in which the results depend on the cooperation of two people and you want to get the best result. Your partner in this task would be Adam, Player 1 from the game described above. You would feel (put an $\mathrm{X}$ on the scale below reflecting your feelings):

Imagine another task that requires people to collaborate in which you can choose your partner for the task/project. As a partner, you would prefer:

definitely Adam

(Player 1 from

the above game) definitely a person other than Adam

(Player 1 from the above game)

Due to the planned statistical analyses, please provide demographic information.

You are:

woman

man

Age:

years old

Is your first language Polish?

YES

Have you ever come across the game described above?

YES 